\title{
Influence of salinization on seeds germination of the fodder semi-shrub of the eastern saltwort (Salsola orientalis S.G. Gmel.)
}

\author{
Elmira Shamsutdinova* \\ FWRC FPA, the Moscow region, 141055 Lobnya, Russia
}

\begin{abstract}
Eastern saltwort (Salsola orientalis S. G. Gmel.) belongs to the goosefoot family (Chenopodiaceae Vent.), the genus Salsola L., a semishrub with $25-70 \mathrm{~cm}$ high with fleshy leaves. It is distributed on saline sandy loam and stony soils from plains to low mountains. It is widely used to restore productivity of degraded natural pastures in arid regions of Russia and Central Asia countries. It is characterized by good palatability, nutritional value, exceptional resistance to salt stress, drought and other adverse environmental conditions. The objective of the study is to find out the effect of different salt concentrations on the germination of eastern saltwort seeds. The influence of various types of salinization on the germination of eastern saltwort seeds in concentrations was tested $(0.2$; $0.4 ; 0.6 ; 0.8 ; 1.0 ; 1.2 ; 1.4 ; 1.6 ; 1.8$ and $2.0 \%$ to the absolutely dry mass of sand): chloride, sulphate, sulphate-chloride, chloride-sulphate, control sand moistened with distilled water. With chloride salinization at concentrations of $0.2-0.4 \%$, the germination energy and germination of eastern saltwort seeds decreased slightly, and at concentrations of 1.2$1.4 \%$, germination stopped. Sulfate salinization was the least toxic. With all types of salinization, with an increase in the salt concentration, the sowing - germination period is delayed and the process of germination of eastern saltwort seeds is expanded. Although eastern saltwort is a true halophyte, its seeds germinate better on a nonsaline substrate.
\end{abstract}

\section{Introduction}

Soil degradation due to salinity, alkalinity, or their combined effect is one of the factors limiting the optimal use of land resources.

About $10 \%$ of the continental surface is covered with saline soils, which are more common in arid regions. The problem of salinization is serious in 75 countries of the world. Significant areas of saline land are found in Australia, China, India, Iraq, Mexico, Pakistan, and the United States [1]. Salinization and soil alkalinity processes are particularly pronounced in the Southern regions of the country. According to G.A. Romanenko et al. [2] data, saline soils in Russia occupy 45 million hectares.

\footnotetext{
*Corresponding author: darplant@list.ru
} 
Long-term research of the Federal Williams Scientific Center of Forage Production and Agroecology and other scientific institutions selected promising salt-resistant species and forms of fodder plants from the natural flora. Among the promising plant species that are most resistant to salt stress and water deficit, and are able to form a sufficiently high feed production, there was a fodder semi-shrub - eastern saltwort (Salsola orientalis S.G. Gmel.) [3].

Eastern saltwort (Salsola orientalis) belongs to the goosefoot family (Chenopodiaceae Vent.), the genus Salsola L., a semi-shrub with $25-70 \mathrm{~cm}$ high with fleshy leaves. The number of chromosomes $2 \mathrm{n}=72$. It is distributed on saline sandy loam and stony soils from plains to low mountains. The area is Central Asia, Kazakhstan, Iran, and Western China [4, 5]. This plant has recently been widely used to restore the productivity of degraded natural pastures in the arid regions of Russia and Central Asia countries. It is characterized by good palatability, nutritional value, exceptional resistance to salt stress, drought and other adverse environmental conditions. In the phase of regrowth and branching, i.e. during the period of pasture ripeness, eastern saltwort pasture feed contains $19-20 \%$, in the budding flowering phase - $17.6-18 \%$ of protein, respectively, in $100 \mathrm{~kg}$ of dry matter $-71-74$ feed units. High fodder values, resistance to extreme environmental factors, and extremely high variability of the eastern saltwort in terms of ecological, biological, and economic characteristics are an important prerequisite for its introduction into culture to restore the productivity of arid pastures.

Animal breeders highly appreciate the feed advantages of eastern saltwort, consider it as a fattening feed.

Long-term research of scientists [5-7] has shown the ecological stability, high fodder value and prospects of this semi-shrub for restoring the productivity of degraded natural arid pastures. Since in arid climates, soils are usually saline, it became necessary to find out the ratio of semi-shrub germinating seeds to salinity.

In this regard, the objective of our study is to find out the effect of different concentrations of salts (chlorides, sulfates and their mixtures) on the germination of eastern saltwort seeds.

\section{Materials and methods}

The influence of various types of salinization on the germination of eastern saltwort seeds was tested in the following concentrations (in \% of the absolutely dry sand mass):

- $\quad$ chloride $(\mathrm{NaCl})-0.2 ; 0.4 ; 0.6 ; 0.8 ; 1.0 ; 1.2 ; 1.4 ; 1.6 ; 1.8$ and 2.0 ;

- $\quad$ sulphate $\left(\mathrm{Na}_{2} \mathrm{SO}_{4}\right)-0.2 ; 0.4 ; 0.6 ; 0.8 ; 1.0 ; 1.2 ; 1.4 ; 1.6 ; 1.8 ; 2.0 ; 2.2$;

- $\quad$ sulfate-chloride $\left(\mathrm{NaCl}+\mathrm{MgSO}_{4}-2: 1\right)-0.2 ; 0.4 ; 0.6 ; 0.8 ; 1.0 ; 1.2 ; 1.4 ; 1.6 ; 1.8$; $2.0 ; 2.4 ; 2.8 ; 3.2$;

- $\quad$ chloride-sulfate $\left(\mathrm{NaCl}+\mathrm{MgSO}_{4}+\mathrm{Na}_{2} \mathrm{SO}_{4}-1: 1: 2\right)-0.2 ; 0.4 ; 0.6 ; 0.8 ; 1.0 ; 1.2$; $1.4 ; 1.6 ; 1.8 ; 2.0 ; 2.4 ; 2.8 ; 3.2$;

- $\quad$ control - sand moistened with distilled water.

The seeds were sprouted in Petri dishes on quartz sand moistened with a solution of salts up to $60 \%$ of the total moisture capacity. The set humidity was maintained throughout the entire experiment. The seeds of the eastern saltwort were laid out on wet sand, slightly buried for closer contact with the salted substrate. During the first day, Petri dishes with sown seeds were kept in the refrigerator at a temperature of $+3 \ldots+5^{\circ} \mathrm{C}$, after which they were transferred to the thermostat, where the temperature was maintained at $+20 \ldots+23^{\circ} \mathrm{C}$ throughout the germination period. The repetition is fourfold. Records were taken daily; seedlings were removed; the energy of germination was noted on the $10^{\text {th }}$ day after the first shoots appeared, which began to appear two days after the experiment was laid. 


\section{Results and discussion}

B.P. Strogonov [8] believes that chloride salinization at $1 \%$ concentration causes the death of the main mass of seeds $(75 \%)$, and at $2 \%$ - their complete death. From an ecological point of view, it is important to find out the influence of soil salinity on seed germination.

In this regard, it seems correct to consider the effect of each type of salinity separately on seed germination.

Chloride salinization. It should be noted that with a slight chloride salinity of $0.2-0.4 \%$, the seeds of eastern saltwort gave a fairly high percentage of germination 77.25-71.0, respectively. The germination energy was $63.5-56.0 \%$. At a concentration of $0.8 \%$, it decreased sharply $-9 \%$, at a concentration of $1.0 \%$, the total germination rate was $15.5 \%$. At a concentration of $1.2 \%$, almost all seeds of eastern saltwort did not germinate (table 1 ).

Table 1. Effect of chloride salinization on the germination of eastern saltwort seeds, \%.

\begin{tabular}{|c|c|c|c|c|c|c|c|}
\hline \multirow{2}{*}{ Date } & \multicolumn{7}{|c|}{ Cerminated seeds, \% } \\
\cline { 2 - 8 } & \multicolumn{7}{|c|}{ Concentration, \% } \\
\cline { 2 - 8 } & 0.2 & 0.4 & 0.6 & 0.8 & 1.0 & 1.2 & control \\
\hline 26.01 & 3.5 & 1.25 & 0.5 & 0.25 & 0 & 0 & 28.0 \\
\hline 27.01 & 11.75 & 4.75 & 1.0 & 0.25 & 0 & 0 & 37.25 \\
\hline 28.01 & 8.75 & 9.75 & 2.25 & 1.75 & 0 & 0 & 9.75 \\
\hline 29.01 & 9.75 & 6.5 & 4.25 & 0.5 & 0 & 0 & 4.5 \\
\hline 30.01 & 9.75 & 8.0 & 3.75 & 1.5 & 0.25 & 0 & 5.0 \\
\hline 31.01 & 6.5 & 6.0 & 2.75 & 4.0 & 0.25 & 0 & 5.5 \\
\hline 01.02 & 2.25 & 3.25 & 1.75 & 2.25 & 0 & 0 & 0.75 \\
\hline 02.02 & 5.5 & 5.75 & 7.5 & 5.25 & 1.0 & 0.33 & 1.0 \\
\hline 03.02 & 4.5 & 5.0 & 1.25 & 2.75 & 0.25 & 0 & 1.5 \\
\hline 04.02 & 1.0 & 3.25 & 3.25 & 3.0 & 0.75 & 0 & 0.75 \\
\hline $\begin{array}{c}\text { Germination } \\
\text { energy, \% }\end{array}$ & $63.5 \pm 3.6$ & $56.0 \pm 4.1$ & $28.3 \pm 3.6$ & $9.0 \pm 3.2$ & $1.8 \pm 0.4$ & $0.33 \pm 0.3$ & $94.0 \pm 1.1$ \\
\hline $05-10.02$ & 7.75 & 12.0 & 17.25 & 10.0 & 1.75 & 1.0 & 1.75 \\
\hline $11-15.02$ & 4.0 & 2.0 & 6.75 & 7.0 & 4.75 & 0 & 0.75 \\
\hline $16-20.02$ & 0.75 & 1.5 & 1.5 & 1.5 & 1.75 & 0 & 0.25 \\
\hline $21-28.02$ & 1.5 & 2.0 & 3.25 & 2.25 & 4.75 & 0 & 0 \\
\hline Total & $77.3 \pm 2.5$ & $71.0 \pm 3.0$ & $59.3 \pm 3.8$ & $23.3 \pm 5.9$ & $15.5 \pm 2.9$ & $1.3 \pm 0.8$ & $97.0 \pm 1.3$ \\
\hline
\end{tabular}

The salinity of sand in the range of $0.6-1.0 \%$, along with a decrease in germination leads to a strong expansion of the seed germination process over time.

\subsection{Sulphate salinization}

Seed germination and germination energy gradually decrease as the concentration of potassium sulphate increases from 0.2 to $1.4 \%$. At $1.8 \%$ salinity, there is a decrease in germination - $6.0 \%$ and seed germination energy - 4.0\%. When comparing the concentration of $0.2 \%$ with the control experiment, the difference in germination was only $10 \%$ in favor of the control (table 2).

Table 2. Effect of sulphate salinity on the germination of eastern saltwort seeds, \%.

\begin{tabular}{|c|c|c|c|c|c|c|c|}
\hline \multirow{3}{*}{ Date } & \multicolumn{7}{|c|}{ Germinated seeds } \\
\cline { 2 - 8 } & \multicolumn{7}{|c|}{ Concentration, \% } \\
\cline { 2 - 8 } & 0.2 & 0.6 & 0.8 & 1.2 & 1.4 & 1.8 & control \\
\hline 26.01 & 10.25 & 1.0 & 0.5 & 0 & 0 & 0 & 28.0 \\
\hline 27.01 & 13.5 & 5.75 & 2.75 & 0.5 & 1.25 & 0 & 37.25 \\
\hline
\end{tabular}




\begin{tabular}{|c|c|c|c|c|c|c|c|}
\hline 28.01 & 12.0 & 8.5 & 4.75 & 1.25 & 1.0 & 0 & 9.75 \\
\hline 29.01 & 11.75 & 8.0 & 5.75 & 1.0 & 1.25 & 0.75 & 4.5 \\
\hline 30.01 & 8.5 & 7.75 & 7.25 & 3.75 & 3.25 & 0.25 & 5.0 \\
\hline 31.01 & 6.75 & 8.0 & 7.25 & 4.75 & 1.75 & 0.25 & 5.5 \\
\hline 01.02 & 1.75 & 2.5 & 2.75 & 1.25 & 1.5 & 0.5 & 0.75 \\
\hline 02.02 & 3.0 & 5.0 & 5.25 & 6.5 & 4.5 & 1.0 & 1.0 \\
\hline 03.02 & 0.75 & 4.0 & 1.5 & 3.75 & 0.5 & 0.5 & 1.5 \\
\hline 04.02 & 2.0 & 3.0 & 2.0 & 2.25 & 2.25 & 0.75 & 0.75 \\
\hline $\begin{array}{c}\text { Germination } \\
\text { energy, \% }\end{array}$ & $76.3 \pm 2.2$ & $53.5 \pm 3.4$ & $39.8 \pm 2.8$ & $25.0 \pm 5.1$ & $17.3 \pm 3.6$ & $4.0 \pm 2.4$ & $94.0 \pm 1.1$ \\
\hline $05-10.02$ & 5.0 & 10.0 & 10.5 & 9.0 & 6.25 & 3.25 & 1.75 \\
\hline $11-15.02$ & 2.0 & 5.25 & 3.25 & 3.75 & 2.75 & 2.0 & 0.75 \\
\hline $16-20.02$ & 1.75 & 2.5 & 3.25 & 1.5 & 0.5 & 0 & 0.25 \\
\hline $21-28.02$ & 2.0 & 2.5 & 2.75 & 4.5 & 5.25 & 2.0 & 0 \\
\hline Total & $87.0 \pm 1.0$ & $73.8 \pm 2.4$ & $59.0 \pm 3.4$ & $37.8 \pm 4.9$ & $31.0 \pm 7.8$ & $6.0 \pm 1.08$ & $97.0 \pm 1.3$ \\
\hline
\end{tabular}

With this type of salinization, the germination period is also extended with an increase in salt concentration, but not as much as with chloride.

Sulfate-chloride salinization. Concentrations of $0.2-0.6 \%$ do not have such a negative effect on germination and seed germination energy (table 3). Only at a higher salinity level of $0.8-1.2 \%$, a significant decrease in germination and germination energy of eastern saltwort seeds was recorded. The lowest seed germination $-1.25 \%$ was observed at a concentration of $1.4 \%$, and at a concentration of 1.8 and $2.0 \%$, the seeds did not germinate. There is also the extension of germination period of eastern saltwort seeds, starting from a concentration of $0.6 \%$.

Chloride-sulfate salinization. Table 4 data indicate that with this type of salinization, the seeds of eastern saltwort retain a fairly high percentage of germination $-60.75-84.25 \%$, as well as a high germination energy $-40.0-72.0 \%$.

With an increase in the salt concentration to $1.2 \%$, there is a gradual decrease in the number of germinated seeds $-51.0 \%$, and with a further increase in the concentration of $1.6-2.0 \%$, the percentage of sprouted seeds sharply decreases $9.33-21.25 \%$. The most unfavorable type of salinity is chloride, followed by sulfate-chloride.

Table 3. Effect of sulphate-chloride salinization on the germination of eastern saltwort seeds, $\%$.

\begin{tabular}{|c|c|c|c|c|c|c|c|}
\hline \multirow{2}{*}{ Date } & \multicolumn{7}{|c|}{ Germinated seeds } \\
\cline { 2 - 8 } & \multicolumn{7}{|c|}{ Concentration, \% } \\
\cline { 2 - 8 } & 0.2 & 0.6 & 1.0 & 1.2 & 1.4 & 1.8 & control \\
\hline 26.01 & 12.25 & 0.5 & 0.25 & 0.25 & 0 & 0 & 28.0 \\
\hline 27.01 & 13.25 & 4.75 & 0.25 & 0 & 0 & 0 & 37.25 \\
\hline 28.01 & 12.5 & 5.75 & 0 & 0 & 0 & 0 & 9.75 \\
\hline 29.01 & 7.5 & 7.5 & 0.25 & 0.5 & 0 & 0 & 4.5 \\
\hline 30.01 & 7.5 & 7.0 & 1.5 & 0.25 & 0 & 0 & 5.0 \\
\hline 31.01 & 5.75 & 5.0 & 2.25 & 0.5 & 0 & 0 & 5.5 \\
\hline 01.02 & 3.5 & 4.0 & 2.25 & 0.75 & 0 & 0 & 0.75 \\
\hline 02.02 & 2.25 & 5.75 & 3.75 & 0.5 & 0 & 0 & 1.0 \\
\hline 03.02 & 1.5 & 3.75 & 2.0 & 0.25 & 0 & 0 & 1.5 \\
\hline 04.02 & 2.75 & 3.5 & 2.0 & 0 & 0.5 & 0 & 0.75 \\
\hline $\begin{array}{c}\text { Germination } \\
\text { energy, \% }\end{array}$ & $68.5 \pm 2.4$ & $47.5 \pm 5.9$ & $14.5 \pm 2.2$ & $3.0 \pm 1.2$ & $0.5 \pm 0.28$ & 0 & $94.0 \pm 1.1$ \\
\hline $05-10.02$ & 6.5 & 9.25 & 7.75 & 3.5 & 0 & 0 & 1.75 \\
\hline $11-15.02$ & 2.5 & 4.0 & 2.0 & 1.0 & 0.25 & 0 & 0.75 \\
\hline $16-20.02$ & 2.0 & 1.5 & 1.0 & 0 & 0 & 0 & 0.25 \\
\hline
\end{tabular}




\begin{tabular}{|c|c|c|c|c|c|c|c|}
\hline $21-28.02$ & 2.5 & 4.0 & 3.5 & 6.5 & 0.5 & 0 & 0 \\
\hline Total & $82.0 \pm 0.7$ & $67.3 \pm 6.3$ & $28.8 \pm 4.6$ & $14.0 \pm 4.1$ & $1.3 \pm 0.6$ & 0 & $97.0 \pm 1.3$ \\
\hline
\end{tabular}

Table 4. Effect of chloride-sulphate salinity on the germination of eastern saltwort seeds, $\%$.

\begin{tabular}{|c|c|c|c|c|c|c|c|}
\hline \multirow{2}{*}{ Date } & \multicolumn{7}{|c|}{ Germinated seeds } \\
\cline { 2 - 8 } & \multicolumn{7}{|c|}{ Concentration, \% } \\
\cline { 2 - 8 } & 0.2 & 0.6 & 1.0 & 1.2 & 1.4 & 2.0 & control \\
\hline 26.01 & 18.75 & 2.75 & 0 & 0 & 0 & 0 & 28.0 \\
\hline 27.01 & 14.25 & 6.0 & 1.0 & 0.5 & 0 & 0 & 37.25 \\
\hline 28.01 & 9.0 & 5.0 & 2.0 & 1.0 & 0 & 0 & 9.75 \\
\hline 29.01 & 8.5 & 11.5 & 5.5 & 2.25 & 0.5 & 0.25 & 4.5 \\
\hline 30.01 & 8.5 & 11.25 & 4.75 & 1.25 & 0.5 & 0.5 & 5.0 \\
\hline 31.01 & 5.75 & 5.0 & 2.25 & 0.5 & 0 & 0 & 5.5 \\
\hline 01.02 & 2.75 & 4.5 & 2.75 & 1.25 & 1.0 & 0 & 0.75 \\
\hline 02.02 & 2.0 & 6.75 & 10.75 & 8.75 & 0.75 & 0.25 & 1.0 \\
\hline 03.02 & 2.75 & 3.5 & 4.25 & 3.75 & 0.75 & 0.5 & 1.5 \\
\hline 04.02 & 3.25 & 2.75 & 4.75 & 5.75 & 1.0 & 0.25 & 0.75 \\
\hline 05.02 & 2.25 & 1.5 & 4.25 & 5.5 & 1.0 & 0.5 & 0 \\
\hline $\begin{array}{c}\text { Germination } \\
\text { energy, \% }\end{array}$ & $72.0 \pm 0.9$ & $55.0 \pm 2.3$ & $40.0 \pm 2.4$ & $30.0 \pm 3.7$ & $5.5 \pm 1.5$ & $2.3 \pm 1.0$ & $94.0 \pm 1.1$ \\
\hline $06-11.02$ & 6.75 & 7.25 & 15.75 & 11.25 & 6.0 & 2.25 & 1.75 \\
\hline $12-16.02$ & 2.25 & 2.5 & 5.0 & 5.5 & 6.5 & 1.25 & 0.75 \\
\hline $17-21.02$ & 1.0 & 2.25 & 1.25 & 1.5 & 0 & 0 & 0.25 \\
\hline $22-28.02$ & 1.25 & 1.75 & 3.0 & 3.0 & 2.75 & 1.25 & 0 \\
\hline Total & $84.3 \pm 1.9$ & $68.8 \pm 2.8$ & $60.8 \pm 4.6$ & $51.0 \pm 2.6$ & $21.3 \pm 5.3$ & $9.3 \pm 2.9$ & $97.0 \pm 1.3$ \\
\hline
\end{tabular}

When sodium sulphate salinization, especially at low concentrations, the highest percentage of germinated seeds is obtained, and with an increase in concentrations (from $0.8 \%$ ), this type of salinization gives way to chloride-sulfate.

Sulfate-chloride salinization is less toxic than chloride salinization but is significantly inferior to chloride-sulfate salinization.

Control germination on sand moistened with distilled water showed that although eastern saltwort is a typical halophyte, its seeds germinate better on a nonsaline background. This is consistent with the statement of Heinrich Lundegaard [9] that halophyte seeds have an optimum germination not in salt, but in nonsaline water, and therefore their resistance to salt is considered as an ontogenetic adaptation.

\section{Conclusion}

With chloride salinization at concentrations of $0.2-0.4 \%$, the germination energy and germination of eastern saltwort seeds decrease slightly, and at concentrations of $1.2-1.4 \%$, germination stops. Sulfate salinization is the least toxic. Chloride-sulfate salinization at concentrations of $0.2-0.6 \%$ is slightly inferior to salinization with sodium sulfate. With all types of salinization, with an increase in the salt concentration, the sowing - germination period is delayed and the process of germination of eastern saltwort seeds is expanded. Although eastern saltwort is a true halophyte, its seeds germinate better on a nonsaline substrate.

\section{Acknowledgment}


The research was supported by a grant from the Russian Science Foundation (project no. 19-16-00114).

\section{References}

1. J.D. Rhoades, A. Kandiah, A.M. Mashali, The use of saline waters for crop production. FAO irrigation and drainage paper, 48 (1992)

2. G.A. Romanenko, I.P. Kruzhilin, M.S. Grigorov, V.I. Olgarenko, V.V. Melikhov, A.G. Bolotin, Problems of desertification and protection of biological diversity of natural complexes of arid regions of Russia (2003)

3. Z.Sh. Shamsutdinov, N.Z. Shamsutdinov, Halophyte crop production (ecological and biological bases) (2005)

4. N.I. Akzhigitova, Halophilic vegetation of Central Asia and its indicative properties (1982)

5. Botanical geography of Kazakhstan and Central Asia (within the desert region) (2003)

6. R. Aslam, N. Bostan, N. Amen, M. Maria and W. Safdar, J. of Medicinal Plants Research. 5, 33 (2011)

7. M.-N. Grigore, M. Villanueva, M. Boscaiu and O. Vicente, Not. Sci. Biol., 4, 2 (2012)

8. B.P. Strogonov, Physiological bases of salt tolerance of plants (1962)

9. G. Lundegaard, The influence of climate and soil on plant life (1937) 